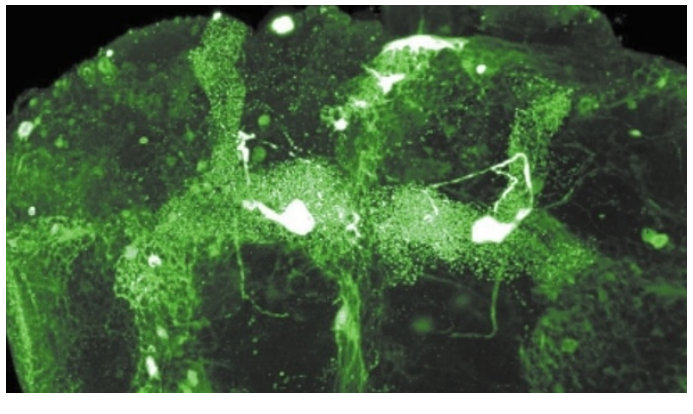

\section{Flying down memory lane}

A recent report from Joseph T. Lurito and his colleagues at Indiana University School of Medicine indicates that there might be gender-based differences in temporal lobe activity during passive listening. Briefly, listening elicited bilateral temporal lobe activation in females, whereas activation in males was mostly seen in just one hemisphere. This work, presented at the Meeting of the Radiological Society of North America, immediately caught the attention of the media, triggering a profusion of headlines, most of which linked the findings to the alleged inability of males to listen to what they are told.

Women use more of brain when listening, study says.

\section{Confirming what many} women have long suspected, new brain research released Tuesday shows that men give only half a mind to what they hear, listening with just one side of the brain while women use both

Los Angeles Times 29 Nov.

You weren't listening dear ...

The proof is in for something women long have suspected: men listen with only one side of their brains while women use both sides.

Reuters $28 \mathrm{Nov}$

\section{Using half a brain - it's a guy thing, study says.}

Chicago Tribune 29 Nov.

Fortunately, most of the reports went on to explain in more accurate terms the findings and their possible interpretation. However, in an age when the public's grasp of science is a key aspect of science policy, it is important to transcend the funny headline when disseminating scientific findings. Unless, of course, the public use only half their brain when reading.

Peter Collins and Juan Carlos López
The amnesiac (amn) gene was identified over 20 years ago in a behavioural screen for Drosophila memory mutants. Flies were tested for their ability to associate a specific odour with an electric shock. Initially, flies mutant at the amn locus could learn as well as their wild-type counterparts, but they were unable to retain the memory for over 60 minutes.

Associative olfactory memory is processed in specialized structures of the Drosophila brain known as mushroom bodies (MBs), and several olfactory learning genes are expressed in the MB-intrinsic Kenyon cells. In the 22 November issue of Cell, Waddell et al. demonstrate that the amn gene is an exception to the rule. The amn gene encodes the neuropeptide AMN, which shows some sequence homology to the mam-

\section{DENDRITES}

\section{Counting channels one by one}

Take a guess: how many $\mathrm{Ca}^{2+}$ channels are there in a spine? 50 ? 100 ? 500 ? Well, guess again. By using $\mathrm{Ca}^{2+}$ imaging and relatively simple statistical methods, Sabatini and Svoboda have obtained evidence that there are no more than 20 , typically around five channels per spine. This amazing observation is likely to put a new perspective on our sense of scale when thinking about the molecular organization of the synapse. Sabatini and Svoboda measured action-potential-mediated $\mathrm{Ca}^{2+}$ transients in individual spines, making sure that the rise in $\mathrm{Ca}^{2+}$ was due to opening of spine channels, and not to dendritic channels. They measured the trial-to-trial fluctuations in the amplitude of the transients and analysed them using the same statistical tools used for conventional quantal analysis of neurotransmission. They calculated the coefficient of variation for the $\mathrm{Ca}^{2+}$ increases and the probability of failure to elicit a transient to then obtain estimates of the number of malian pituitary-adenylyl-cyclaseactivating peptide (PACAP). AMN stimulates the cyclic AMP signal transduction pathway, which is important for the memory process in the fly and other species. Waddell et al. showed that AMN is predominantly expressed in two large neurons, the dorsal paired medial (DPM) cells. The DPM cell bodies lie outside the MBs, but their processes form an extensive network of branches that innervate the MB lobes.

To demonstrate that signalling from the DPM cells is important for olfactory memory, the researchers temporarily inactivated neurosecretion in these cells. This manipulation resulted in a phenocopy of the $a m n$ mutation. They also showed that reestablishment of amn expression in mutant DPM cells was able to restore
Two amn -positive DPM neurons (white) innervating the mushroom bodies. Courtesy of Scott Waddell, MIT, Massachusetts, USA

memory retention, an effect that could not be replicated by expressing the gene in MB-intrinsic neurons.

Secretion of AMN by the DPM cells is therefore likely to be essential for establishing associative olfactory memory in Drosophila. This is the first demonstration of peptidergic modulation of olfactory learning by neurons projecting to the MBs.

Heather Wood

6.) References and links ORIGINAL RESEARCH PAPER Waddell, S. et al. The amnesiac gene product is expressed in two neurons in the Drosophila brain that are critical for memory. Cell 103, 805-813 (2000) FURTHER READING Feany, M. B. \& Quinn, W. G. A neuropeptide gene defined by the Drosophila memory mutant amnesiac. Science 268, 869-873 (1995)

WEB SITE William Quinn's lab

ENCYCLOPEDIA OF LIFE SCIENCES Memon in fruit flies and nematodes channels and their probability of opening at individual spines. Their methods, which make it possible to image the function of single channels, allowed the authors to show that $\mathrm{Ca}^{2+}$ channels had a $50 \%$ chance of opening on any given trial. They also found that the number of channels was between one and 20 , depending on the size of the spine. Perhaps this paucity of channels is not so surprising given that, based on structural considerations, few glutamate receptors have similarly been predicted to exist in the postsynaptic density. What is more surprising is that such a handful of molecules can endow the synapse with its proverbial capacity for plasticity. The fact that there are so few molecules of any given type implies that changes in one or two might be enough to alter significantly the efficacy of synaptic transmission, and implies the existence of regulatory mechanisms that are capable of maintaining the delicate balance among the few components of the synapse. Is there an intimate, almost 'personal', recognition between a channel or a receptor and the proteins in charge of regulating its activity? What mechanisms ensure that the right number of channels will be present at a spine of a given size? The observations of Sabatini and Svoboda raise profound questions about the workings of the synapse and highlight the potential of optical methods to tackle questions that have remained elusive to our arsenal of electrophysiological techniques.

Juan Carlos López

(2) References and links ORIGINAL RESEARCH PAPER Sabatini, B. L. \& Svoboda, K. Analysis of calcium channels in $593(2000)$ FURTHER READING Yuste, R. et al. From form to function: calcium compartamentalization in dendritic spines. Nature Neurosci. 3, 653-659 (2000) | Magee, J. C. \& Johnston, D. Characterization of single voltage-gated $\mathrm{Na}^{+}$and $\mathrm{Ca}^{2+}$ channels in apical dendrites of rat CA1 pyramidal neurons. J. Physiol. 487, 67-90 (1995) ENCYCLOPEDIA OF LIFE SCIENCES Dendritic spines | Calcium channel blockers WEB SITE Karel Svoboda's laboraton 